\title{
TìNH HìNH TỬ VONG DO UNG THU' TẠI TỈNH ĐIỆN BIÊN NĂM 2017
}

\author{
Phạm Cẩm Phương ${ }^{1}$, Nguyễn Phương Hoa² và Hoàng Thị Hải Vân"凶 \\ ${ }^{1}$ Bệnh viện Bạch Mai \\ ${ }^{2}$ Trường Đại học Y Hà Nội
}

Nghiên cứu nguyên nhân tử vong giúp cho việc đánh giá gánh nặng bệnh tật. Nghiên cứu này nhằm mô tả tình hình tử vong do ung thư tại tỉnh Điện Biên năm 2017. Đây là một nghiên cứu mô tả cắt ngang, thu thập số liệu của tất cả các trường hợp tử vong tại Điện Biên trong năm 2017. Kết quả nghiên cứu cho thấy tỷ lệ tử vong do ung thư tại Điện Biên là 11,2\%, trong đó tỷ lệ tử vong do ung thư phổi và ung thư gan đứng thứ 5 và thứ 8 trong số các nguyên nhân gây tử vong tại đây. Các trường hợp tử vong do ung thư tại Điện Biên gặp ở nhiều lứa tuổi khác nhau trong đó độ tuổi 50-59 chiếm tỷ lệ cao nhất (26\%). Tỷ lệ tử vong do ung thư ở nam cao hơn ở nữ ( $p<0,05)$. Các bệnh ung thư gây tử vong hàng đầu tại Điện Biên bao gồm ung thư phổi, ung thư gan, ung thư dạ dày, ung thư vòm họng ở nam giới và ung thư phổi, ung thư gan và ung thư cổ tử cung, ung thư vú ở nứ giới. Tỷ lệ tử vong do ung thư tại Điện Biên tương tự như tỷ lệ tử vong do ung thư chung của toàn quốc. Loại ung thư phổ biến gây tử vong ở cả nam giới và nữ giới là ung thư phổi và ung thư gan.

Từ khóa: Tử vong, ung thư, Điện Biên, trạm y tế.

\section{I. ĐẠT VẤN ĐÈ}

Ung thư đang trở thành gánh nặng lớn và ngày càng gia tăng tại các quốc gia trên thế giới, đặc biệt với các quốc gia có thu nhập thấp và trung bình do gánh nặng kinh tế cho bệnh nhân, hệ thống chăm sóc sức khỏe và quốc gia phải chi tiêu nhiều hơn cho chăm sóc sức khỏe, thiệt hại về năng suất lao động do bệnh tật và tử vong sớm. ${ }^{1}$ Hiện nay, ung thư là nguyên nhân gây tử vong hàng đầu, chỉ đứng sau bệnh lý về tim mạch, với 9,6 triệu người tử vong trên thế giới năm 2018, cứ 6 người tử vong trên thế giới thì 1 người tử vong do ung thư. ${ }^{2}$ Trong số hơn 100 loại bệnh ung thư khác nhau hiện nay phổ biến nhất là ung thư phổi, ung thư vú, ung thư đại trực tràng, ung thư tiền

Tác giả liên hệ: Hoàng Thị Hải Vân

Trường Đại học Y Hà Nội

Email: hoangthihaivan@hmu.edu.vn

Ngày nhận: 18/12/2020

Ngày được chấp nhận: 28/01/2021 liệt tuyến, ung thư da và ung thư dạ dày, trong đó các bệnh ung thư gây tử vong nhiều nhất trên thế giới là ung thư phổi, ung thư đại trực tràng, ung thư dạ dày, ung thư gan và ung thư vú. ${ }^{2}$ Ung thư đang là mối đe dọa hàng đầu đối với người dân và là gánh nặng của ngành y tế, khi bệnh đang ngày càng có xu hướng gia tăng; phần lớn được phát hiện khi đã ở giai đoạn muộn nên việc điều trị vô cùng phức tạp và tốn nhiều chi phí. ${ }^{3}$

Tính đến tháng 11 năm 2020, theo Tổ chức nghiên cứu ung thư quốc tế, số ca hiện mắc ung thư trên thế giới khoảng trên 50 triệu người, số ca mắc mới là trên 19 triệu ca. ${ }^{3}$ Điều đáng nói khoảng $70 \%$ bệnh nhân ung thư sống ở các nước có thu nhập thấp và trung bình. ${ }^{4}$ Việt Nam là một trong những nước có tỷ lệ mắc bệnh cao, mỗi năm có hơn 300.000 bệnh nhân đang điều trị bệnh ung thư khoảng 165.000 ca mắc mới và 115.000 bệnh nhân tử 
vong do ung thư (năm 2018), trong đó ung thư gan đã vượt qua ung thư phổi trở thành ung thư thường gặp nhất. Nhìn tổng quan trên bản đồ ung thư thế giới, tỉ lệ mắc ung thư của Việt Nam không quá cao nhưng tî̉ lệ tử vong tương đối lớn, xếp vị trí 56/185 quốc gia và vùng lãnh thổ với tỉ lệ 104,4/100.000 dân. ${ }^{5}$

Số liệu về tử vong là một trong những chỉ số y tế quan trọng nhất nhằm đo lường tình trạng sức khỏe và y tế của từng địa phương, khu vực, quốc gia. Đặc biệt với các nước có thu nhập thấp và trung bình, các dữ liệu về tử vong đóng vai trò quan trọng trong việc hỗ trợ chuyển đổi hệ thống y tế sang chất lượng cao thông qua việc sử dụng dữ liệu để vận động, giải trình và hành động. ${ }^{6}$ Tầm quan trọng của các chỉ số đo lường tử vong còn thể hiện trong hai mục tiêu của kế hoạch phát triển Thiên Niên Kỷ và là một trong ba yếu tố cấu thành nên chỉ số phát triển con người của Liên hợp quốc. Việc tìm hiểu mô hình tử vong, trong đó có nguyên nhân tử vong do ung thư được coi là một điều kiện thiết yếu trong định hướng các hoạt động y tế và hỗ trợ việc xây dựng chính sách dựa trên bằng chứng đối với từng địa phương, khu vực. Nhằm cung cấp thông tin về tình hình tử vong tại Điện Biên cho các nhà quản lý và hoạch định chính sách chung của tỉnh cũng như trong lĩnh vực y tế của tỉnh, chúng tôi tiến hành nghiên cứu Tình hình tử vong do ung thư tại tỉnh Điện Biên năm 2017.

\section{II. ĐỐI TƯƠ'NG VÀ PHƯƠNG PHÁP}

\section{1. Đối tượng}

Địa điểm nghiên cứu: Nghiên cứu được thực hiện tại 100 xã thuộc tỉnh Điện Biên.

Đối tượng và thời gian nghiên cứu: Nghiên cứu được tiến hành đối với tất cả các trường hợp tử vong từ 01/01/2017 đến 31/12/2017 với mọi lứa tuổi tại 100 xã trong tổng số 130 đơn vị cấp xã thuộc tỉnh Điện Biên (9 phường, 5 thị trấn và 116 xã). Đây là 100 xã đã được hướng dẫn và ghi chép sổ A6 cụ thể theo nguyên nhân trong khi các xã khác mới chỉ ghi lại số lượng tử vong với nguyên nhân chung là bệnh mất hoặc già mất. Mặt khác tại 100 xã này công tác ghi chép tử vong và nguyên nhân tử vong do bác sĩ tiến hành trong khi các xã khác chưa có bác sĩ, chỉ có y sĩ khám bệnh.

Tổng số trường hợp tử vong thuộc địa bàn của 100 xã ở tỉnh Điện Biên ghi nhận được trong điều tra này là 2856 trường hợp.

Thông tin của tất cả các trường hợp tử vong thuộc địa bàn xã được ghi nhận trong sổ ghi chép tử vong (A6/TYT) của trạm y tế xã, (thực hiện theo thông tư số 27/2014/TT-BYT, năm 2014). Các trường hợp tử vong được xác định do nguyên nhân ung thư khi cán bộ trạm y tế xã ghi nhận được thông tin (do người thân cung cấp) của các cơ sở y tế tuyến trên về chẩn đoán và điều trị bệnh (hóa trị, phẫu thuật, xạ trị, chăm sóc giảm nhẹ...)

Thời gian thu thập số liệu: thu thập số liệu từ tháng 4-9/2019.

\section{Phương pháp}

Thiết kế nghiên cứu: Nghiên cứu mô tả cắt ngang.

Các biến số nghiên cứu: bao gồm các thông tin đặc điểm đối tượng nghiên cứu (tuổi, giới, nghề nghiệp), các thông tin liên quan đến tử vong (địa điểm tử vong, chẩn đoán nguyên nhân tử vong do các cơ sở y tế tuyến trên về chẩn đoán và điều trị).

Để hạn chế sai số có thể xảy ra, chỉ lấy các trương hợp tử vong do tuyến trên chẩn đoán, loại các trường hợp tử vong chỉ ghi nguyên nhân là bệnh mất chung chung và già mất. 
Số liệu được nhập và quản lý bằng phần mềm Epidata 3.1 ; phân tích bằng phần mềm Stata 11.1. Test khi bình phương $\left(X^{2}\right)$ được sử dụng để so sánh sự khác biệt giữa các nhóm. Mức có ý nghĩa thống kê là $p<0,05$. Nguyên nhân tử vong sẽ được phân tích theo các nhóm bệnh dựa vào phân loại quốc tế bệnh tật ICD-10.

\section{3. Đạo đức nghiên cứu}

Nghiên cứu này chỉ sử dụng phương pháp thu thập số liệu đã được ghi nhân sẵn ở sổ ghi chép tử vong A6/TYT của hệ thống y tế. Kết quả nghiên cứu chỉ phục vụ công tác nghiên cứu khoa học và xây dựng kế hoạch chăm sóc sức khỏe của địa phương.

\section{KẾT QUẢ}

Điều tra ghi nhận được 2856 trường hợp tử vong tại tỉnh Điện Biên trong năm 2017, có 1786 đối tượng là nam chiếm 62,5\%, nữ giới có 1070 trường hợp $(37,5 \%)$. Kết quả điều tra cho thấy tỉ lệ tử vong của nhóm người cao tuổi ( $\geq 60$ tuổi) cao nhất với 41,6\%. Có $68,8 \%$ các trường hợp với nghề nghiệp là làm ruộng. Đa số các trường hợp là tử vong tại nhà, chiếm tỉ lệ $77,9 \%$; chỉ có 15,2\% là tử vong tại cơ sở y tế.

Bảng 1. Một số đặc điểm của các trường hợp tử vong tại tỉnh Điện Biên

\begin{tabular}{|c|c|c|c|}
\hline \multicolumn{2}{|c|}{ Đặc điểm chung } & \multirow{2}{*}{$\begin{array}{c}\text { Số lượng } \\
670\end{array}$} & \multirow{2}{*}{$\begin{array}{c}\text { Tỷ lệ (\%) } \\
23,4\end{array}$} \\
\hline \multirow{4}{*}{ Nhóm tuổi } & 0 - 14 tuổi & & \\
\hline & 15 - 49 tuổi & 710 & 24,9 \\
\hline & 50 - 59 tuổi & 288 & 10,1 \\
\hline & $\geq 60$ tuổi & 1188 & 41,6 \\
\hline \multirow{2}{*}{ Gióoi tính } & Nam & 1786 & 62,5 \\
\hline & Nữ & 1070 & 37,5 \\
\hline \multirow{2}{*}{ Nghề nghiệp } & Làm ruộng & 1964 & 68,8 \\
\hline & Khác & 892 & 31,2 \\
\hline \multirow{3}{*}{ Địa điểm tử vong } & Tại nhà & 2225 & 77,9 \\
\hline & Tại cơ sở y tế & 434 & 15,2 \\
\hline & Nơi khác & 197 & 6,9 \\
\hline
\end{tabular}

Kết quả điều tra ghi nhận được 320 trường hợp tử vong do ung thư, chiếm tỷ lệ 11,2\% trong số 2856 tất cả các trường hợp tử vong được ghi nhận. 
Tỉ lệ \%

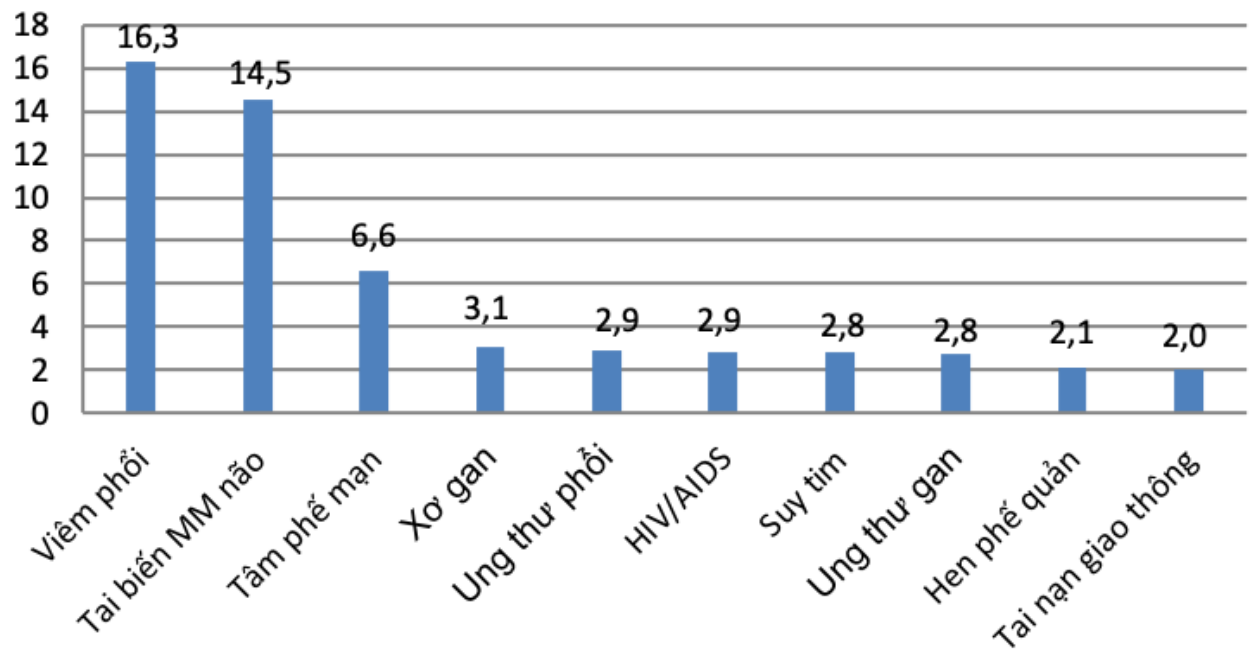

Biểu đồ 1. Mười nguyên nhân gây tử vong nhiều nhất ( $\mathrm{n}=2856)$

Biểu đồ 1 cho thấy với 2856 trường hợp tử vong trong năm 2017 được điều tra, trong số 10 nguyên nhân gây tử vong hàng đầu, tử vong do ung thư góp mặt 2 nguyên nhân là ung thư phổi (đứng hàng thứ 5 ) và ung thư gan (đứng hàng thứ 8 ).

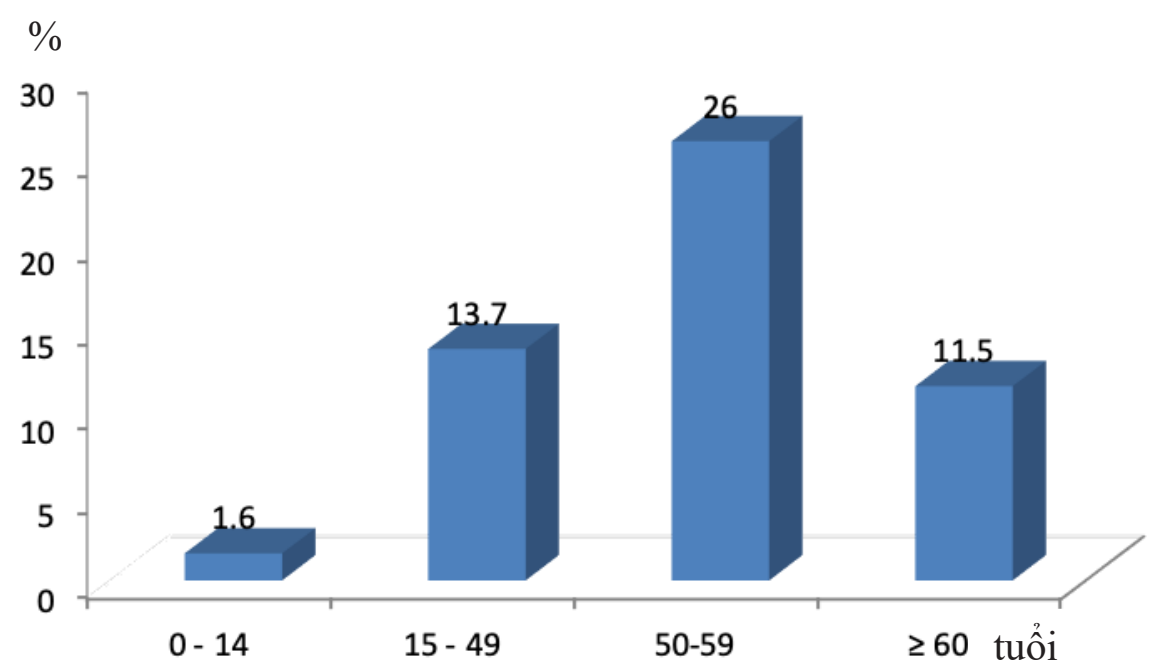

Biểu đồ 2. Phân bố tử vong do ung thư trong các trường hợp tử vong theo nhóm tuổi

$$
\text { ( } n=2856)
$$

Biểu đồ 2 cho thấy tỷ lệ tử vong do ung thư thấp nhất là trẻ em $(1,6 \%)$ và cao nhất là nhóm tuổi từ 50 - 59 tuổi $(26 \%)$. Sự khác biệt về tỷ lệ tử vong do ung thư giữa các nhóm có ý nghĩa thống kê với $p<0,05$. 
Bảng 2. Tỷ lệ tử vong do ung thư theo nhóm tuổi và giới ( $\mathrm{n=2856)}$

\begin{tabular}{|c|c|c|c|c|c|}
\hline \multirow{3}{*}{ Tuổi } & \multicolumn{2}{|c|}{ Nam } & \multicolumn{2}{|c|}{ Nũr } & \multirow{3}{*}{$p$} \\
\hline & \multirow{2}{*}{ Tổng số TV } & Ung thur & \multirow{2}{*}{ Tổng số TV } & \multirow{2}{*}{$\begin{array}{c}\text { Ung thur } \\
n(\%)^{\#}\end{array}$} & \\
\hline & & $n(\%)^{\#}$ & & & \\
\hline $0-14$ & 380 & $8(2,1)$ & 290 & $3(1,0)$ & 0,368 \\
\hline $15-49$ & 522 & $60(11,5)$ & 188 & $37(19,7)$ & 0,005 \\
\hline $50-59$ & 219 & $53(24,2)$ & 69 & $22(31,9)$ & 0,205 \\
\hline$\geq 60$ & 665 & $100(15,0)$ & 523 & $37(7,1)$ & 0,000 \\
\hline Tổng & 1786 & $221(12,4)$ & 1070 & $99(9,3)$ & 0,012 \\
\hline
\end{tabular}

\#Số TV do ung thư/ tổng số trường hợp tử vong của từng nhóm tuổi

Kết quả điều tra cho thấy tỷ lệ tử vong do ung thư ở nam giới cao hơn ở nữ giới, sự khác biệt này có giá trị thống kê $(12,4 \%$ so với $9,3 \% ; p<0,05)$. Ở cả hai giới tử vong do ung thư cao nhất là nhóm tuổi từ 50-59 tuổi (nam 24,2\%, nữ 31,9\%).

Tỉ lệ \%

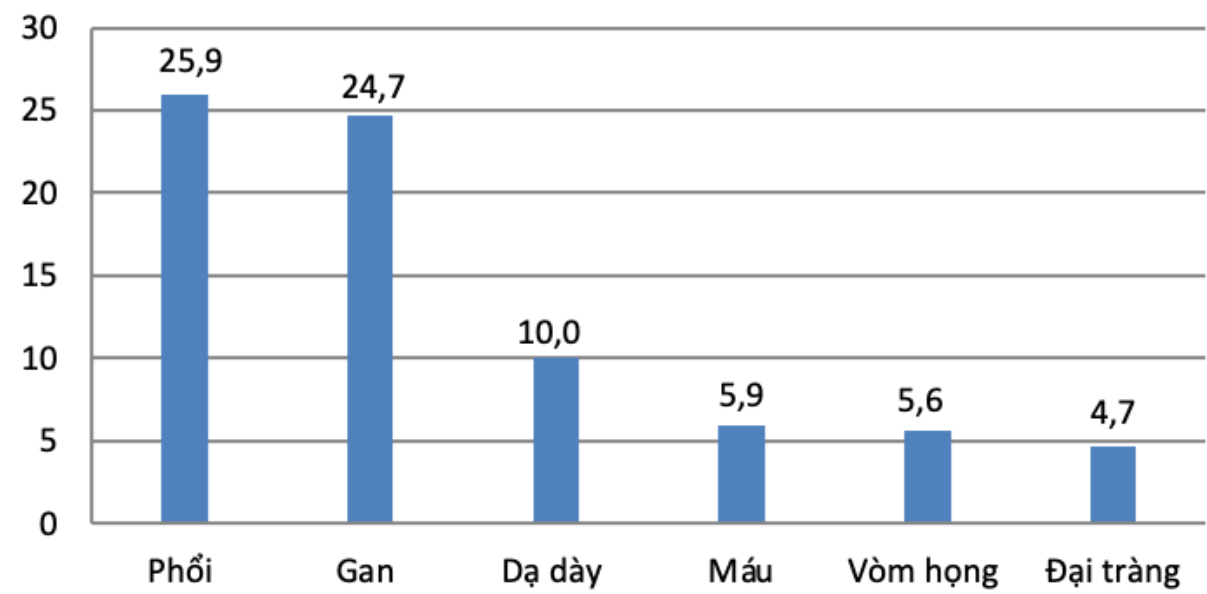

Biểu đồ 3. Phân bố một số loại ung thư gây tử vong thường gặp ( $n=320$ THTV do ung thư)

Kết quả ở Biểu đồ 3 cho thấy tỷ lệ tử vong do ung thư phổi đứng đầu trong các loại ung thư, chiếm $25,9 \%$. Xếp thứ hai là do ung thư gan chiếm tỉ lệ $24,7 \%$. Nguyên nhân do ung thư dạ dày chiếm hàng thứ ba với tỉ lệ 10,0\%. 


\section{Bảng 3. Một số loại ung thư gây tử vong thường gặp theo giới tính}

\begin{tabular}{|c|c|c|c|c|c|}
\hline \multirow{2}{*}{ Loại ung thư } & \multicolumn{2}{|c|}{ Nam } & \multicolumn{2}{|c|}{ Nữ } & \multirow{2}{*}{$\mathrm{p}$} \\
\hline & $\mathbf{n}$ & $\%^{*}$ & $\mathbf{n}$ & $\%^{*}$ & \\
\hline Ung thư phổi & 64 & 29,0 & 19 & 19,2 & 0,065 \\
\hline Ung thu gan & 64 & 29,0 & 15 & 15,2 & 0,008 \\
\hline Ung thư dạ dày & 20 & 9,0 & 12 & 12,1 & 0,397 \\
\hline Ung thư máu & 11 & 5,0 & 8 & 8,1 & 0,278 \\
\hline Ung thư vòm họng & 14 & 6,3 & 4 & 4,0 & 0,410 \\
\hline Ung thư đại tràng & 10 & 4,5 & 5 & 5,1 & 0,783 \\
\hline Ung thư cổ tử cung/TC & & & 14 & 14,1 & \\
\hline Ung thư vú & & & 10 & 10,1 & \\
\hline Ung thư tuyến tiền liệt & 8 & 3,6 & & & \\
\hline Các loại ung thư khác & 30 & 13,6 & 12 & 12,1 & \\
\hline Tổng & 221 & 100,0 & 99 & 100,0 & \\
\hline
\end{tabular}

*Số ung thư từng loại/ tổng số các loại ung thư

Ba loại ung thư thường gặp ở cả hai giới là ung thư phổi (nam 29,0\%, nữ 19,2\%), ung thư gan (nam $29,0 \%$, nữ 15,2\%) và ung thư dạ dày (nam 9,0\%; nữ 12,1\%). Trong đó tỉ lệ ung thư gan của nam giới cao hơn ở nữ giới, sự khác biệt có giá trị thống kê $(p<0,05)$. Ung thư vú và cổ tử cung là một trong 5 loại ung thư thường gặp nhất ở nữ giới (với tỉ lệ lần lượt 10,1\% và 14,1\%).

\section{BÀN LUẬN}

Tỷ lệ tử vong do ung thư trong nghiên cứu của chúng tôi là $11,2 \%$ tương tự số liệu tử vong do ung thư của Việt Nam theo thống kê vào năm $2020(11,2 \%),{ }^{7}$ thấp hơn so với tỷ lệ tử vong của Việt Nam năm 2018 (12,0\%), ${ }^{8}$ tương đương với với 1,12 người / 10 tử vong có nguyên nhân là do ung thư cao hơn so với con số này trên thế giới (trên thế giới cứ 6 người tử vong thì có 1 người tử vong do ung thư). So với một số quốc gia trong khu vực Việt Nam có tỷ lệ tử vong do ung thư cao hơn Thái Lan $(10,22 \%),{ }^{9}$ thấp hơn Singapore $(13,5 \%)^{10}$ và cao hơn tỷ lệ chung của khu vực Đông Nam Á (7,81\%). ${ }^{11}$

Tỷ lệ tử vong do ung thư tại Điện Biên ở nư giới thấp hơn ở nam giới (12,4\% so với 9,3\%, $p=0,012)$, kết quả này tương tự như số liệu của quốc gia (15\% so với $8 \%$ ). ${ }^{7}$ Nhóm tuổi có tỷ lệ tử vong do ung thư cao nhất là nhóm tuổi từ 50-59 tuổi (26\%). Điều này có thể giải thích là do có rất nhiều các yếu tố nguy cơ có thể ảnh hưởng trực tiếp tới cả hai giới ở độ tuổi này. Nam giới thì do ảnh hưởng của lối sống như lạm dụng thuốc lá, rượu, bia... Nữ giới thì đang trong độ tuổi thay đổi đặc điểm sinh học, thay đổi nội tiết như sinh đẻ, tiền mãn kinh...

Kết quả của nghiên cứu cũng chỉ ra rằng, tỷ lệ tử vong do ung thư gan và ung thư phổi ở nam giới là cao nhất (đều chiếm 29\%), sau đó là ung thư dạ dày. Kết quả này cũng tương tự con số thống kê của Việt Nam năm 2020.7 
Trên thế giới ung thư hay gặp nhất ở nam giới là ung thư phổi, tiếp đến là ung thư tuyến tiền liệt, đại tràng, thực quản. ${ }^{3}$ Trong khi đối với nữ giới, tại Điện Biên tỷ lệ tử vong do ung thư phổi chiếm tỷ lệ cao nhất, sau đó đến ung thư gan và ung thư vú, kết quả này khác với con số chung của cả nước (cao nhất là ung thư vú, sau đó đến ung thư phổi, ung thư đại tràng, ung thư gan). Có thể thấy ung thư gan là nguyên nhân gây tử vong hàng đầu ở Việt Nam (đứng đầu ở nam giới và đứng thứ 4 ở nữ), nguyên nhân do người dân tại nhiều vùng nông thôn vẫn có thói quen uống rượu nhiều và uống rượu "suông" tức uống rượu mà không ăn, thêm vào đó phương pháp nấu rượu theo phương pháp truyền thống vẫn còn nhiều, tỷ lệ cồn trong rượu cao, do đó tỷ lệ xơ gan và ung thư gan ở Việt Nam ngày càng tăng (năm 2000 là 5,787 ca mắc mới, năm 2010 là 9,372 ca mắc mới và năm 2018 lên đến 19,586 ca mắc mới). ${ }^{12}$ Hơn nữa khi người dân phát hiện ra bị ung thư và thường ở giai đoạn muộn, người dân - nhất là ở các vùng nông thôn, họ không có điều kiện chữa trị theo Tây y, mà toàn chữa thuốc nam vì vậy tỷ lệ tử vong do ung thư ở Việt Nam vẫn còn cao và liên tục tăng qua các năm với với 164,671 ca mới mắc, 114,871 ca tử vong và 303,033 hiện mắc ung thư năm 2018 và 182,563 ca mới mắc, 122,690 ca tử vong và 353,826 ca hiện mắc ung thư năm 2020.5,7,12

Nghiên cứu còn một số hạn chế, thứ nhất là nghiên cứu chỉ phân tích số liệu của tỉnh Điện Biên, không đại diện cho vùng miền hay toàn quốc nên không thể suy rộng kết quả. Thứ hai thiết kế nghiên cứu là mô tả cắt ngang nên chỉ cung cấp thông tin về nguyên nhân tử vong tại tỉnh ở thời điểm nghiên cứu. Do đó cần có những nghiên cứu rộng hơn và theo dõi dọc nhiều năm hơn sẽ cho những kết quả có ý nghĩa hơn.

\section{KÉT LUẬN}

Tỷ lệ tử vong có nguyên nhân ung thư chung ở Điện Biên năm 2017 là 11,2\%. Tỷ lệ tử vong do ung thư ở nam giới $(12,4 \%)$ cao hơn ở nữ giới (9,3\%). Nhóm tuổi 50-59 tuổi có tỷ lệ tử vong do ung thư nhiều nhất (26\%).

Ung thư phổi, gan và dạ dày là ba loại ung thư hàng đầu hay gặp nhất ở nam giới. Ở nữ giới là ung thư phổi, gan và cổ tử cung.

\section{TÀI LIẸU THAM KHẢO}

1. OECD. Cancer Care: Assuring quality to improve survival. Focus Health. Published online November 2013.

2. WHO. Assessing National Capacity for the Prevention and Control of Noncommunicable Diseases: Report of the 2019 Global Survey.; 2020:116. https://www.who.int/publications/i/ item/ncd-ccs-2019.

3. International Agency Research for cancer. Globalcan 2020 World fact sheet. Published online November 2020. Accessed December 15, 2020. https://gco.iarc.fr/today/data/ factsheets/populations/900-world-fact-sheets. pdf.

4. Cancer. Accessed December 14, 2020. https://www.who.int/news-room/fact-sheets/ detail/cancer.

5. WHO. Cancer in Vietnam. Accessed December 15, 2020. https://www.who.int/ westernpacific/health-topics/cancer.

6. English, M., Mwaniki, P., Julius, T. et al. Hospital Mortality - a neglected but rich source of information supporting the transition to higher quality health systems in low and middle income countries. BMC Med. 2018;16(32). doi:https:// doi.org/10.1186/s12916-018-1024-8.

7. International Agency Research for cancer. Globalcan 2020 Vietnam fact sheets. Published online December 2020. Accessed December 
16, 2020. https://gco.iarc.fr/today/data/ factsheets/populations/704-viet-nam-factsheets.pdf.

8. Bray F, Ferlay J, Soerjomataram I, Siegel RL, Torre LA, Jemal A. Global cancer statistics 2018: GLOBOCAN estimates of incidence and mortality worldwide for 36 cancers in 185 countries. CA Cancer J Clin. 2018;68(6):394424. doi:10.3322/caac.21492.

9. International Agency Research for cancer. Globalcan 2020 Thailand fact sheet. Published online November 2020. Accessed December 16, 2020. https://gco.iarc.fr/today/ data/factsheets/populations/764-thailandfact-sheets.pdf.

10. National Registry of Diseases Office. Singapore Cancer Registry Annual
Report 2015.; 2017. Accessed December 16, 2020. https://www.nrdo.gov.sg/docs/ librariesprovider3/Publications-Cancer/ cancer-registry-annual-report-2015_web. pdf?sfvrsn=10.

11. International Agency Research for cancer. Globalcan South East Asia Region fact sheets. Published online October 2020. Accessed December 16, 2020. https://gco.iarc. fr/today/data/factsheets/populations/995-whosouth-east-asia-region-searo-fact-sheets.pdf.

12. Pham T, Bui L, Kim G, Hoang D, Tran T, Hoang M. Cancers in VietnamBurden and Control Efforts: A Narrative Scoping Review. Cancer Control $J$ Moffitt Cancer Cent. 2019;26(1). doi:10.1177/1073274819863802.

\section{Summary}

\section{MORTALITY OF CANCER IN DIEN BIEN PROVINCE IN 2017}

Information on the cause of death helps to assess the overall burden of diseases. This study is to describe the mortality from cancer in Dien Bien province in 2017 . The research design is a cross-sectional descriptive study, collecting data of all deaths in 2017. Study results showed the death rate from cancer in Dien Bien was $11.2 \%$, of which the death rate from lung cancer and liver cancer ranked 5th and 8th among the causes of death. The ratios are $2.9 \%$ and $2.8 \%$, respectively. Death due to cancer in Dien Bien is found at different ages range, of which the age range of 50-59 represents the highest proportion (26\%). The death rate from cancer is higher in men than in women $(p<0.05)$. The leading deadly cancers in Dien Bien include lung cancer, liver cancer, stomach cancer, nasopharyngeal cancer in men and lung cancer, liver cancer, cervical cancer and breast cancer in women. The death rate from cancer in Dien Bien is similar to the general cancer death rate of the whole country. The most common types of cancer that cause death in men and women are lung cancer and liver cancer.

Keywords: mortality, cancer, Dien Bien, commune health station. 